\title{
A Multimodal Critical Discourse Analysis of the Canadian Federal Election Candidate Justin Trudeau's Facebook Page
}

\author{
A research submitted by \\ Aya Mohamed Khaled Mohamed \\ An M.A student \\ Ain Shams University \\ Faculty of Al-Alsun (Languages) \\ Department of English Language and Translation \\ Linguistics Section
}

A Translator and Reviewer at DB Group

$\underline{\text { Abstract }}$

In the light of 2015 Canadian federal election, the present study conducts a multimodal critical discourse analysis of Justin Trudeau's Facebook images and the captions accompanying them. This is carried out through using Machin's and Mayr's toolkit (2012) that helps conduct multimodal critical discourse analysis of the linguistic and visual modes. This study aims at proving the importance of the other modes along with language, highlighting the linguistic and visual techniques used by the Trudeau in his Facebook page to reveal his ideology, and determining how the two modes work together and complement each other.

Keywords: Multimodality, Multimodal Critical Discourse Analysis, Justin Trudeau, Canadian Federal Election 2015, Facebook, Ideology 


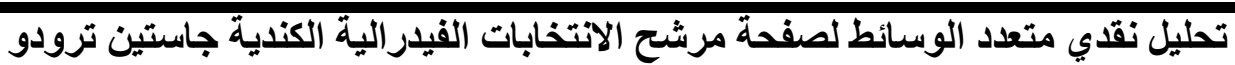

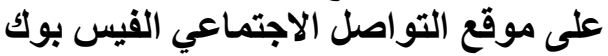

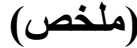

في ضوء الانتخابات الفيدر الية الكندية لعام 10 • ب، يجري الباحث تحليل نقدي

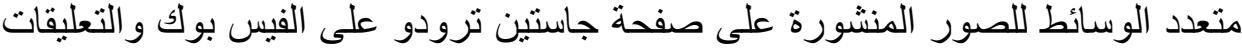

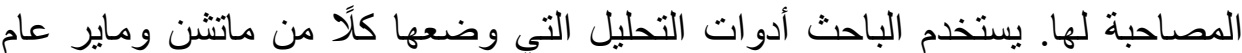

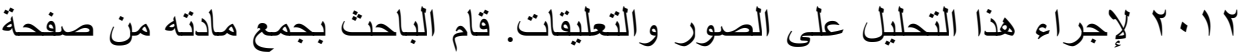

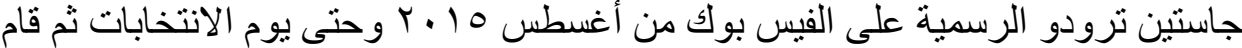

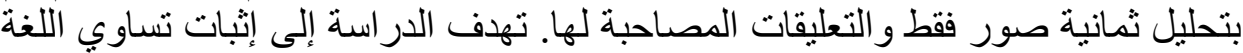

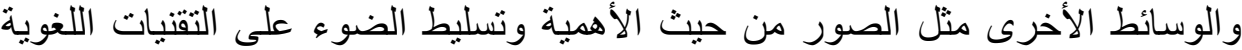

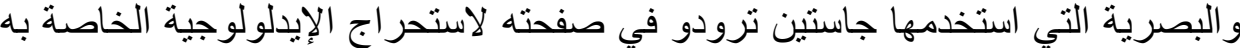

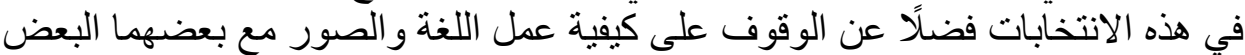

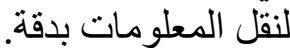

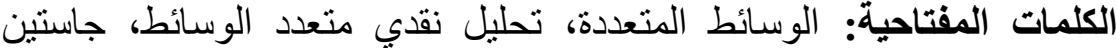

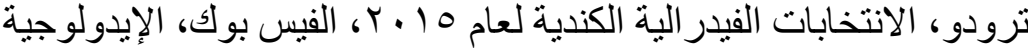




\title{
A Multimodal Critical Discourse Analysis of the Canadian Federal Election Candidate Justin Trudeau's Facebook Page
}

\author{
A research submitted by \\ Aya Mohamed Khaled Mohamed \\ An M.A student \\ Ain Shams University \\ Faculty of Al-Alsun (Languages) \\ Department of English Language and Translation \\ Linguistics Section
}

A Translator and Reviewer at DB Group

\section{Introduction}

\subsection{Context of the study}

The social networking sites have recently grown in importance as a place for political activism. These sites, such as Twitter, YouTube and Facebook, offer ways to engage citizens in political life where electoral campaigns play important role (Tenhunen \& Karvelyte, 2015). They, especially Facebook, have recently had a huge impact on any presidential elections all over the world. Owing to their multimodal nature, these sites enable the researcher to implement a multimodal analysis and prove that the language is not the only important mode that conveys meanings and that the other modes, such as images, are of the same importance. Therefore, the present study tackles the campaign of Justine Trudeau on his Facebook page during 2015 Canadian Federal Election to highlight the major role of the social media in the election and the importance of the other modes such as the images along with the language.

The 2015 Canadian Federal Election is the longest campaign in Canada's history where it started from August 2nd, 2015 and ended on October 19th, 2015. Five parties contested the election, Liberal Party, Conservative Party, New Democratic Party, Bloc Québécois 
and Green party. However, the Liberal Party, Conservative Party and New Democratic Party are the main three parties (Yglesias, 2015). Electing the parliament's members is based on a first-pastthe-post system in which the candidate who obtains the majority of votes in its riding wins the seat. There are 338 ridings in Canada's ten provinces and three territories (Nardelli, 2015).

As mentioned above, the main focus is given to the Liberal Party's leader, Justin Trudeau. Liberal Party is center-left party. It was known as "the natural governing party" as it was the dominant party for 70 years; however, in the past decade it lost dominance and support (Nardelli, 2015).

According to CBC News, the result of the 2015 election was as follows:

Figure 1- Results of 2015 Canadian Federal Election (Federal Election Results 2015. Justin Trudeau's Liberals to form majority

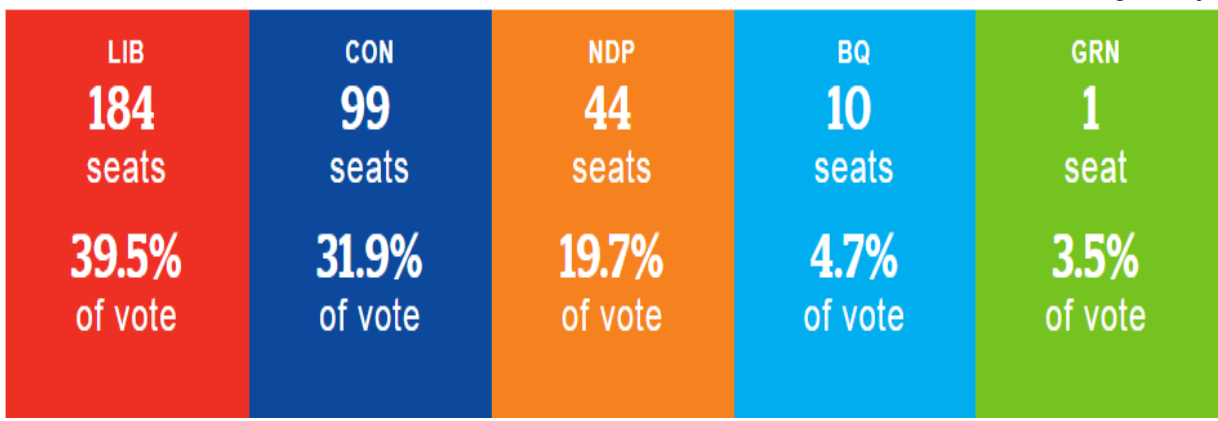

government, 2015)

Liberals won majority after getting 184 of 338 seats and formed a government led by Justin Trudeau as a prime minister (Federal Election Results 2015. Justin Trudeau's Liberals to form majority government, 2015).

\subsection{Objectives of the Study:}

The study in hand carries out multimodal critical discourse analysis of Canadian federal election candidate Justin Trudeau's Facebook page. It detects the linguistic and visual techniques used 


\section{Aya Mohamed Khaled Mohamed}

by him in the images and captions accompanying them to prove how the other modes such as the images are as important as the language in communicating the messages and ideologies.

\subsection{Research Questions:}

1. What are the linguistic and visual techniques used by Trudeau in his Facebook posts to persuade the voters to cast their ballot for him?

2. In what way do the linguistic and visual choices reflect the ideology of the candidate?

3. How do the linguistic and visual modes work together and complement each other in communicating information on the candidate's identity and agenda?

\section{Methodology}

\subsection{Data and Data Collection}

The data is taken from Justin Trudeau's Facebook official page. The researcher is going to analyze eight images from those posted from August 2015 till the Election Day and the captions accompanying them. This data is used due to specific reasons. First, the social media becomes an effective tool in the election so it is important to analyze the candidates' language and images employed to reach the voters and to persuade them to vote. Second, it helps the researcher discover how the linguistic and visual modes work together and shed the light on the equal importance of all modes. Finally, it is full of subtle ideologies; therefore, it is going to get us closer to the candidates.

\subsection{Procedures}

The researcher carries out three main procedures. (1) The researcher starts by downloading posts from August 2015 till the Election Day; (2) the images that include non-English captions and persons other than the candidate are excluded; (3) then the researcher divides the images into two themes (solo images depicting the candidate only and mass appeal images depicting the 
candidate with his supporters); and (4) The most liked eight images are chosen for the analysis.

\subsection{Theoretical Framework}

The present study aims to analyze the images and the captions accompanying them in Trudeau's Facebook page to explore how the linguistic and visual modes work together and unpack the Trudeau's ideology. Therefore, the researcher uses Machin's and Mayer's multimodal critical discourse analysis (MCDA) approach which provides effective linguistic and visual tools to answer the study questions.

\subsection{MCDA Tool}

Machin and Mayer (2012) introduced a toolkit for analyzing the linguistic and visual choices. Such toolkit helps fulfill communicative objectives and unpack the ideology. They suggest that particular verbal and visual choices are made from different resources to communicate, hide, or foreground particular meanings through text or image. Therefore, they presented a comprehensive toolkit. The researcher will analyze the linguistic made in terms of the nominalization, presupposition, people's representation and abstraction and the visual mode in terms of iconography, salience, gaze, pose, distance, angle and representation (Individualization versus collectivization).

\subsubsection{Linguistic Toolkit}

\subsubsection{Nominalization}

Nominalization is a tool used to conceal the agency and responsibility for an action. For example, "The killings of civilians during the bombing raid" (Machin \& Mayer, 2012, p. 138). The use of nominalization has important effects. First, nominalization conceals the responsibility for the action and distracts the reader because the agent and the affected people are obscured. Second, its use also removes any sense of time because it is not associated with

r. r. العدد السادس والعشرون (الجزء الثالث)
مجلة كلية التربية- جامعة عين شمس 


\section{Aya Mohamed Khaled Mohamed}

a tense. Third, it enables us to count, describe and classify the action and can be employed as a new participant. Fourth, in some cases, some nouns turn into stable entities and become common usage. Finally, using nouns enables us to present information in a punchy, compressed style (Machin \& Mayer, 2012, p.p 137-144).

\subsubsection{Presupposition}

Presupposition means the meanings that the addressee is supposed to be familiar with. The importance of the meanings that are provided as given is that they are highly ideological. For example, "British culture is under threat by immigration" (Machin \& Mayer, 2012, p.153). Here the speaker of the sentence presupposes that there is British culture and wants to convey that this culture is threatened to be distorted by immigrants (Machin \& Mayer, 2012, p.p 153).

\subsubsection{Representing people: language and identity}

One of the techniques the communicators use is the representational techniques. Through various choices, the communicators become able to represent the individuals or groups of people as they want and to shed the light on or background particular side of their identity. These choices reflect meanings and ideas that are not explicitly expressed. MCDA classifies the people according to the following: (1) personalization and impersonalisation, (2) individualization versus collectivization, (3) specification and genericisation, (4) nomination or functionalization, (5) honorifics, (6) objectivation, anonymisation, (8) aggregation, (9) pronoun versus noun, and (10) suppression (Machin \& Mayer, 2012, p.77-91).

\subsubsection{Abstraction}

Abstractions mean the rhetorical tropes that are used in the persuasion process. Rhetorical tropes include conceptual metaphor, hyperbole, personification/objectification, metonymy and 
synecdoche (Machin \& Mayer, 2012, p.164). Lakoff and Johnson point out that the conceptual metaphor is a link between two conceptual domains (target domain and source domain) (Evans \& Green, 2006, p.294). For example, "People are machines" (Evans \& Green, 2006, p.297). Hyperbole means exaggeration. For example, "frenzied bloody attack" (Machin \& Mayer, 1992, p.170). Moreover, the agent can also be backgrounded through giving human qualities to concepts or objects and this is called personification/objectification. For example, "Democracy will not stand by while this happens" (Machin \& Mayer, 2012, p.171). Metonymy and synecdoche are also effective rhetorical tropes. Substituting a word or a sentence with a word or a sentence bearing the same meaning is called metonymy. For example, using "Downing Street/The Kremlin said today" instead of (the British /Russian government) (Machin \& Mayer, 2012, p.171). Substituting the whole with a part is called synecdoche. For example, "We need a few bodies to fill the room" (Machin \& Mayer, 2012, p172).

\subsubsection{Visual Toolkit}

\subsubsection{Iconography}

Concerning iconography, according to Machine and Mayer (2012), every image denotes and connotes. Denotation has to do with the elements depicted in the image and connotation has to do with the ideas and values communicated through such elements. For example, in Figure 2, the image denotes a woman in an office that contains a computer, a desk and a handbag under the table connoting the values of glamour, excitement and particular identities (pp. 49-50). 
Figure 2 - image of a woman from Cosmopolitan magazine (Machin \& Mayer, 2012, P.7)

\subsubsection{Salience}

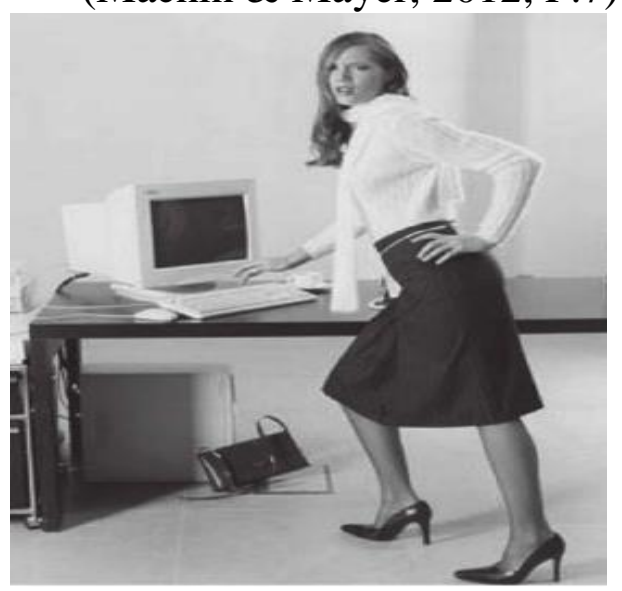

Machine and Mayer (2012) state that salience is about the features that are made noticeable for foregrounding particular meanings and values. Salience can be fulfilled in the images through the following ways: (1) Potent cultural symbols: they are concepts that reflect a particular culture. For example, in Figure 3, the depicted doctor's stethoscope reflects medical practice; (2) Size: the size of the element determines its importance. For example, in Figure 3, the doctor's size is larger than the other members which means that he is more important than them; (3) Color: it has to do with using striking colours, rich saturated colours or contrasts. For example, in Figure 3, the colour of women's faces depicted in the homepage is rich and reflects her satisfaction; (4) Tone: it has to do the brightness of the element. In Figure 4, the women's faces are the brightest elements; (5) Focus: it is used to foreground elements and background others such as the doctor in Figure 3; (6) Foregrounding: it is foregrounding the most important element and putting the others in the background; (7) Overlapping: it is putting an element in front of other. For example, in Figure 3, the doctor overlaps the other members (pp. 54-56) 


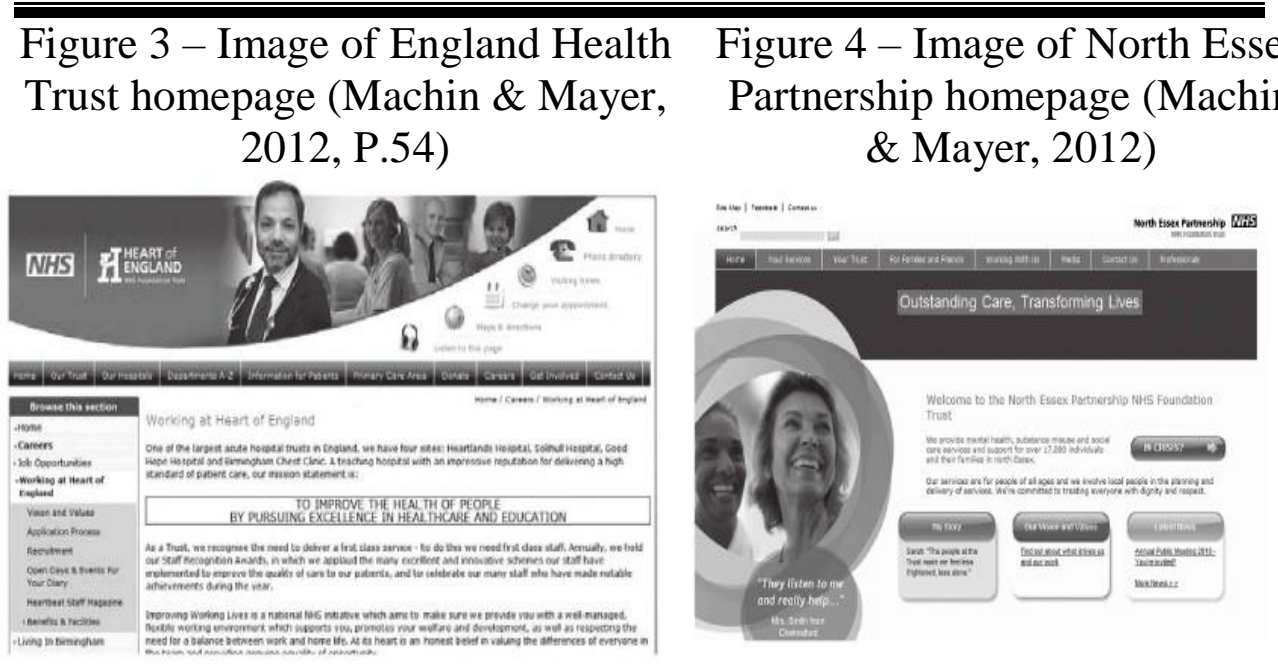

\subsubsection{Gaze}

According to Machin and Mayer (2012), when analyzing the gaze, we have to know in which direction the person depicted looks, whether he looks directly at the viewer, looks off frame, or looks downwards or upwards, in order to be able to evaluate him accurately (p.70). According to Kress and van Leeuwen (1996), speech acts introduced by Halliday can be fulfilled in images. In language, we offer and demand information. They suggest that 'offer' and 'demand' can be fulfilled visually (p.122-123). Thus, the image is either a 'demand image' or an 'offer image'. The 'demand image' is explained through the following example. In Figure 2, the woman looks directly at the viewer and this means two things. First, the viewer is acknowledged. Second, the person depicted waits for a response from the viewer. The other kind is 'offer image'. Here the people depicted do not look at the viewer and no response is required on the part of the viewer as a result as in Figure 4. Besides, the depicted person may look off frame, up or down. For example, the politicians in some images look off frame and slightly upwards to show that they are looking forward to getting a high status and in 


\section{Aya Mohamed Khaled Mohamed}

other images, they look downwards which means that they are worried (Machin \& Mayer, 2012, pp. 72-73).

Figure 5 - image of David Cameron (The Daily Mirror, 16 April 2010) (Machin \& Mayer, 2012, P. 72)
Figure 6 - image of Nick Clegg (The Guardian, 16 April 2010) (Machin \& Mayer, 2012, P. 76)

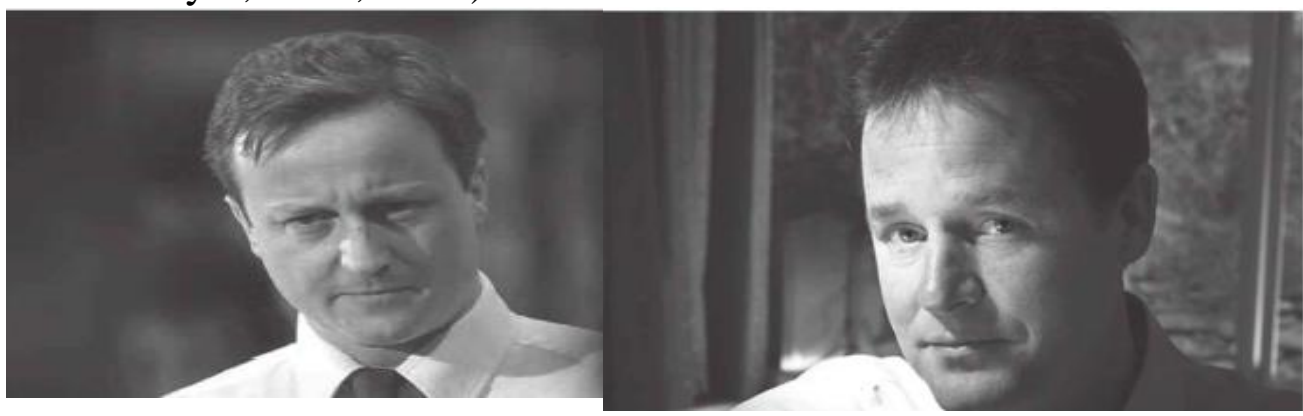

\subsubsection{Pose}

Posture reflects something about the person depicted and unveils their values, ideas, identities and behaviors. For example, in Figure 2, the woman is leaning towards the keyboards and outing her hands on hips. Placing hands on hips expresses her power where she can deal with any person bravely and with determination. Besides, she takes up space by placing her legs apart and her hands on hips. When analyzing pose, the researcher shall determine whether the person depicted takes up space, whether he performs to the viewer or he is self-contained, whether there is relaxation or intensity, whether there is openness or closeness, whether the depicted people reflect the same postures, whether there is intimacy or distance (Machin \& Mayer, 2012, pp. 74-76).

\subsubsection{Distance}

The relations between people are determined through distance where people can distance themselves from those they don't want to connect with or shorten the distance to get close to others. In the visual mode, distance has to do with the size of frame (close, 
medium, or long shot). To illustrate this, the images of British politicians Nick Clegg and David Cameron are closer shots and such angle enables the viewer to examine the inner states and feelings of the politicians depicted (Machin \& Mayer, 2012, p.97).

\subsubsection{Angle}

The angle of the image enables the viewer to engage with the people depicted. We can see what is going on in the image from side-on view which allows a sharedness of position in case it is accompanied with a close shot. In other images, the depicted people confront us as in Figure 3. Although they do not look at us, but the close shot accompanying this angle enables us to observe what they feel. Also, in some images we see the depicted people from behind as in Figure 2, the woman is seen slightly from behind. We can see the image from vertical angle. Here we are positioned to either look down on or up to the depicted people. In Figure 4, we look up at the depicted women and this means that they became powerful after obtaining treatment in this hospital (Machin \& Mayer, 2012, pp.98100). We can also be positioned at the same level and van leeuwen and Jewitt (2001) says that depicting the participant at the same level means equality (p. 135).

\subsubsection{Individualization versus collectivization}

Some visual semiotic resources are available to represent the participants as individuals, groups or anonymous people (Machin \& Mayer, 2012). People can be represented as individuals or group in the image. When they represented as group, they are represented as homogenized. In Figure 2, we will find only one woman depicted in the images while in Figure 3, the hospital's staff is depicted together. Besides, people can visually be represented as specific people. The images may contain a group of black or Jewish people randomly or typical black or Jewish people. The "specific people" image is realized through stereotypical representation and by doing so, the individuality of the people depicted disappears. Some

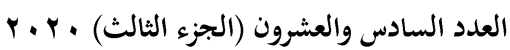

(26)

مجلة كلية التربية- جامعة عين شمس 


\section{Aya Mohamed Khaled Mohamed}

persons can be excluded from the image despite of their presence in the verbal mode (Machin \& Mayer, 2012, pp.100-102).

\section{Literature review}

\subsection{Multimodal Critical Discourse Analysis: Overview and}

\section{Definition}

\subsubsection{Critical Discourse Analysis}

van Dijk (1998) points out that CDA is a vehicle by which we know how power is abused, how dominance is formed and how inequity becomes normal. In addition, it also indicates how such problems are handled by text and talk in the social and political context (p.352).

Machin \& Mayer (2012) state that CDA is used to analyze the news, political speeches, advertisements, etc. shedding the light on the practices that are apparently neutral and aim to represent the events and actors in particular way for fulfilling particular purposes. Accordingly, the term 'critical' means denaturalizing the powers and ideas that are hidden in texts (p. 5). Tenorio (2011) points out that CDA is used to reveal the manipulation practiced by the discursive practices and fight the practices legitimized through the discourse (p.183).

\subsubsection{Multimodal Discourse Analysis}

In the late 1980s and 1999s, it was found that the meaning is formed through other semiotic modes and the nature of the information needs the use of visuality beside language as language is not adequate. At the beginning, it was believed that language is of a high importance compared to the rest of semiotic resources due to its widest range of communicative functions. Afterwards, some scholars stated that no mode is important than the other and the only difference is represented in the possibilities each mode provides for making meaning. O'Halloran also stated that the different semiotic 
resources shall combine and offer their potentials for making meaning (O'Hallorn, Bezemer and Jewitt, 2016, p.3)

O'Hallorn, Bezemer and Jewitt (2016) introduce three key facts of multimodality:

"1- Meaning is made with different semiotic resources, each offering distinct potentialities and limitations.

2- Meaning making involves the production of multimodal wholes.

3- If we want to study meaning, we need to attend to all semiotic resources being used to a complete whole." (P.3).

According to O'Halloran (2011), multimodal discourse analysis (MDA) has to do with analyzing the semiotic resources and the semantic expansion which are presented as semiotic choices in multimodal phenomena and investigating how the multimodal resources are created and distributed in social setting (p.2). O'Halloran (2011) defined MDA as "an emerging paradigm in discourse studies which extends the study of language per se to the study of language in combination with the resources, such as images, scientific symbolism, gesture, action, music and sound" (P.1).

Machin and Mayer (2012) point out that Hodges and Kress (1998) and Kress and van leeuwen (1996) found that the availability of a toolkit that can let them analyze the semiotic resources accurately is necessary. Afterwards, depending on the systemic functional theory of Halliday in 1978, Kress and Leeuwen presented a number of tools that can be employed to analyze the components of image and investigate how such components work together (p.7).

\subsubsection{Multimodal Critical Discourse Analysis}

MCDA studies how the meaning is created in images, photographs, diagrams and graphics shedding the light on the choices made by the image maker and comparing them with the meanings conveyed

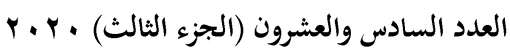

(28)
مجلة كلية التربية- جامعة عين شمس 


\section{Aya Mohamed Khaled Mohamed}

by the linguistic mode. The images and text are a number of choices made by the authors and MCDA aims at detecting these choices through an effective toolkit. MCDA enables us to denaturalize representations in the other semiotic modes for unveiling the ideological ends. In CDA, discourse both shapes and is shaped by society. Similarly, in MCDA, the other modes of communication are a means of social construction. Accordingly, it investigates how the visual choices reflect power relations. MCDA is mainly based on the theories of Gunter Kress, Norman Fairclough, Ruth Wodak and Theo van Leewuen (Machin and Mayer, 2012, pp. 6-10).

\subsection{Approaches}

\subsubsection{Social Semiotics Approach}

Machin and Mayer (2012) points out that this approach to language is different where it focuses on how it is used in the social context and how language is used to create society. In addition, it sheds the light on the way the author employs the semiotics resources, either in language or visual communication, to fulfill their interests. In such approach, the main focus is given to the underlying repertoire of signs in context to convey wider identities and ideas. It states that language and visual communication are shaping the ideologies of the society and contribute to create and legitimate some kinds of social practices (p.17-19). 
A Multimodal Critical Discourse Analysis of the Canadian Federal Election Candidate Justin Trudeau's Facebook Page

\section{Analysis}

\subsection{Solo images depicting the candidate}

\section{First post}

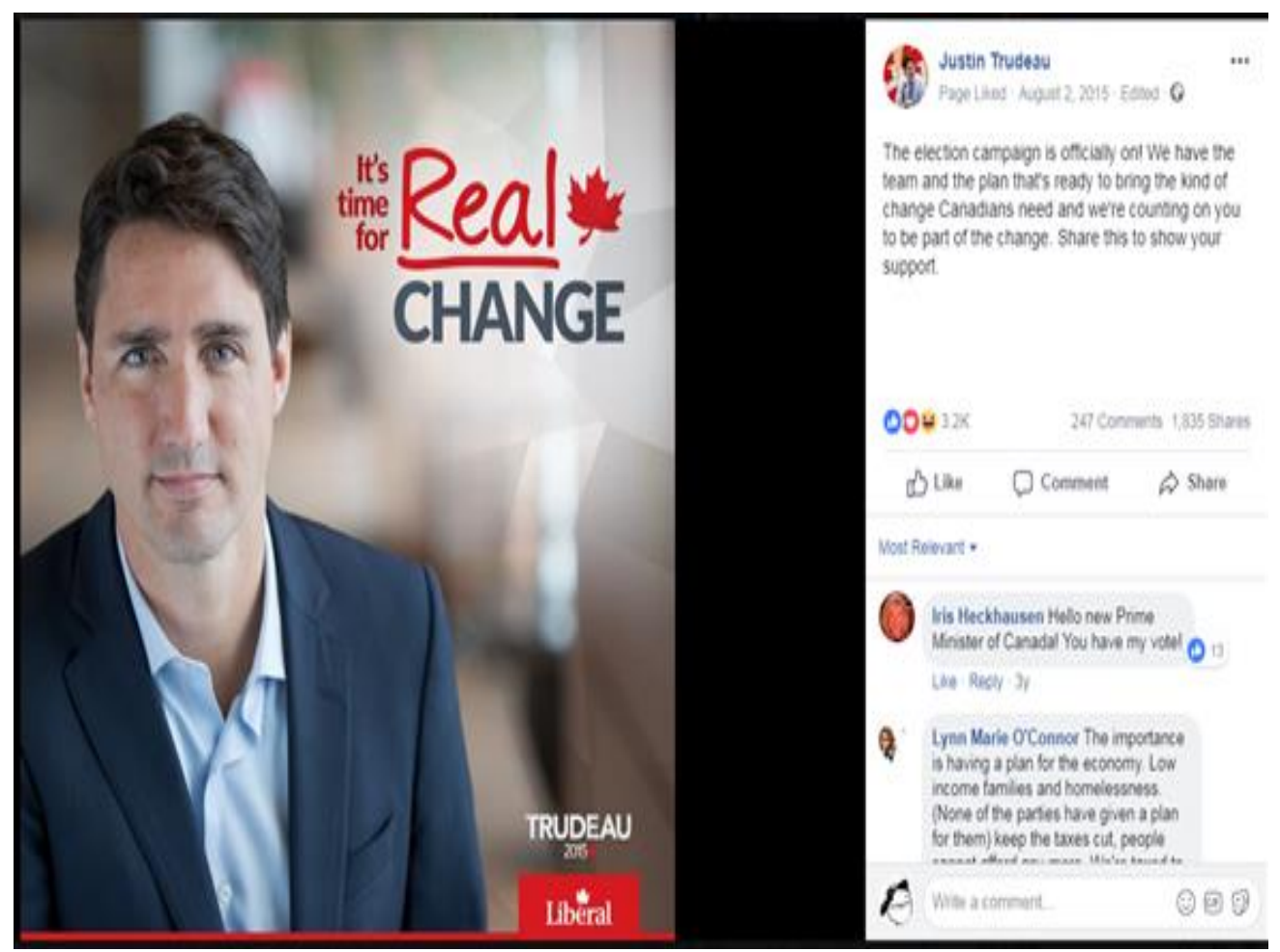

\section{Linguistic Analysis}

The caption is: "The election campaign is officially on! We have the team and the plan that's ready to bring the kind of change

Canadians need and we're counting on you to be part of the change. Share this to show your support."

Text in the image: "It's time for real change." 


\section{Aya Mohamed Khaled Mohamed}

\section{Trudeau uses "the plan", "change" and "support"}

backgrounding agency, time, details of his plans; however, such strategy enables him at the same time to give stirring speech full of hope and. In addition, "change" allows the usage of the verb "bring" to point out that the candidate will exert the efforts necessary to implement the change Canada looks forward to and "support" allows the use of the verb "show" to urge the constituents to take action.

"To bring the kind of change Canadians need", in this sentence presupposes that the old regime's policies were not effective and Canada needs immediate changes. "We're counting on you to be part of the change. Share this to show your support.", it is presupposed that the constituents should have an effective role and join the country's entities in the procedures of change.

There is a conceptual metaphor in the sentence "The election campaign is officially on!" where the election campaign (target domain) can be conceptualized in terms of a race (source domain). The attributes related to the race are transferred into the election campaign, such as competition, speed and preparation. Moreover, in "the plan that's ready to bring the kind of change Canadians need", the plan is personalized and it is granted the ability to carry out the changes the Canadians look forward to. This personification backgrounds who will implement these changes and the actions required for such implementation.

The social actors used here are "We", "You", "Canadians" and "team". Trudeau is talking to all Canadians so that he employed the generalization "Canadians" confirming that every citizen shall have an effective role. In addition, by using "We" and "You", he is getting closer to the voters pointing out that the voters are playing a main role and his party needs their support for carrying out its plans. Generic reference "team" states that Trudeau has the participants necessary to implement his agenda.

r. r. · العدد السادس والعشرون (الجزء الثالث)
مجلة كلية التربية- جامعة عين شمس 
In the image, there is a precise message to the Canadians "It's time for real change.". By using the noun "change", the details of the change and the parties involved in the change are concealed.

\section{Visual Analysis}

The image is simple as it only depicts Trudeau but at the same time it communicates important messages to the viewers. It connotes elegance, simplicity, and new blood. Trudeau is the largest and most salient element in the image. In addition, rich saturated colors, bright tones and focus are used to give Trudeau salience.

Trudeau is looking out at us and this means that the image is a demand one. We

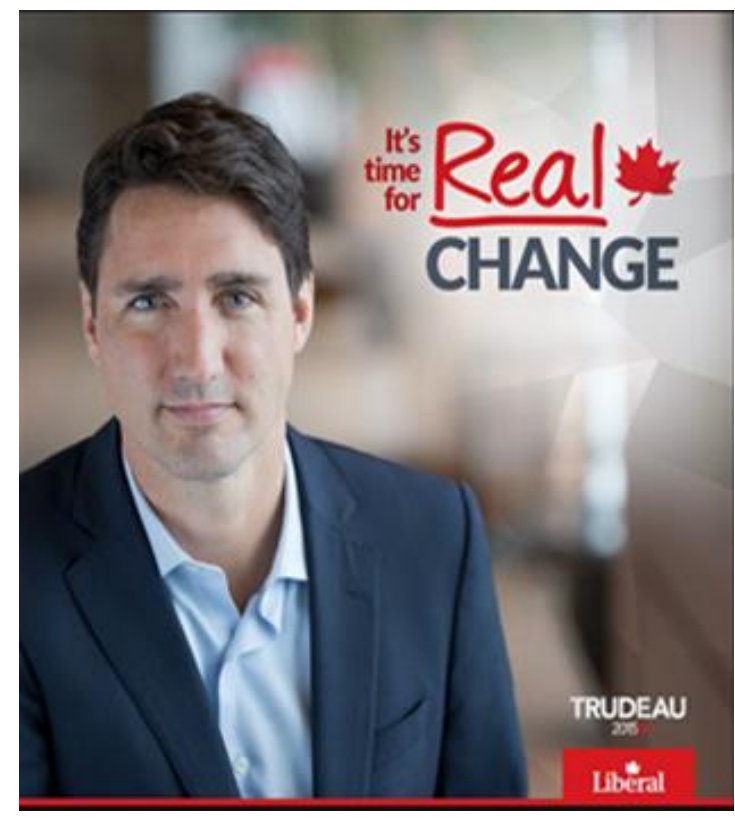
are invited into a relationship with the depicted candidate. Our presence is acknowledged where Trudeau wants us to feel that we are an indispensible component in his journey to the power. $\mathrm{He}$ demands us to vote in favor of him. In addition, the gaze is accompanied by a smile that supports his message to us.

Trudeau's posture suggests stillness; he sits looking relaxed and confident. The pose is a closed one showing relative bodily control. He is photographed in a close shot which makes him taking up physical space. The pose enables us to assess the identity and ideas and here the pose reflects that Trudeau would like to present a confident and approachable character to convince us to support him 


\section{Aya Mohamed Khaled Mohamed}

and his agenda. He is presented as a sincere candidate who would like to let us get to know his ambitions and what he is looking forward to.

We and Trudeau are positioned at the same height and this states that Trudeau is humble and is aware of the Canadians' needs. Moreover, he is individualized visually through being depicted alone and the team mentioned linguistically is visually excluded. The image maker wants to focus on Trudeau and get him the necessary support.

\section{Discovering how the linguistic and visual modes work together, complement each other}

The linguistic and visual modes complement each other well. First, there is a link between the gaze and presupposition. The voters are addressed linguistically and visually. They are linguistically invited to take part in the change through the presupposition. "We're counting on you to be part of the change. Share this to show your support." where it is presupposed that they shall be more positive and support the change. Moreover, the voter also got addressed through the social actors "You" and "We". On the other hand, they are addressed through the gaze where he urges them to be positive and be part of the change.

\section{Second Post}

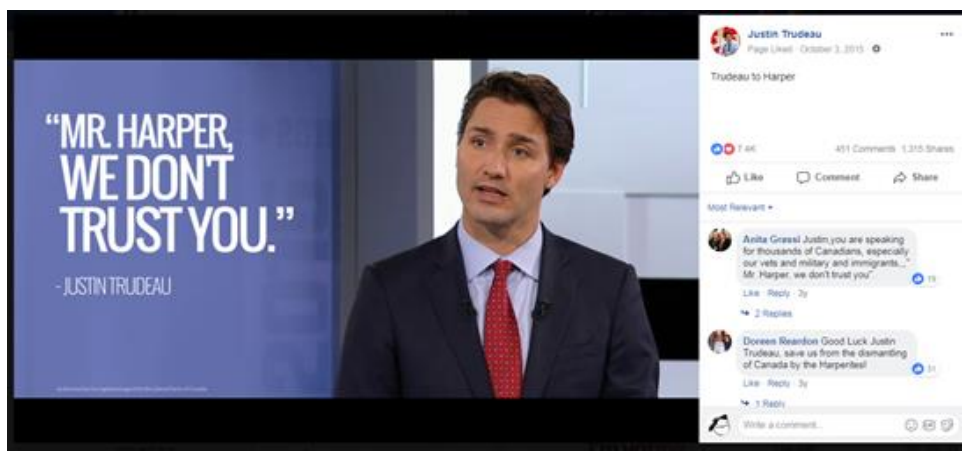

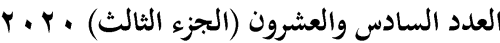

(33)

مجلة كلية التربية- جامعة عين شمس 


\section{Linguistic Analysis}

Text in the image is: "Mr. Harper, we don't trust you" -Justin Trudeau

Trudeau's message is concise and lacks some linguistic strategies. For example, no nominalizations are used where Trudeau avoids presenting the facts through dealing with them as things. Besides, he does not employ abstraction tools to abstract and conceal details. He would like to communicate a direct and obvious message without glossing over anything.

"Mr. Harper, we don't trust you" presupposes that the Canadians suffered a lot throughout nine-year rule term of Harper and his party and that there are problems and negative policies that made the Canadians lose trust in them. Trudeau criticizes the other party and highlights their weaknesses and failures to get the closer to the voters and get their trust. He would like to persuade that casting ballot in favor of him and his party looks like a lifeline that will rescue them.

In terms of the representational strategies, Trudeau uses the pronoun "we" where he is trying to get closer to the voters and their level and he desires to show that he is one of them and that he is also hit by Harper's policies. In other words, he shows that he exactly knows the Canadians' sufferings and needs. This kind of language aims to be trusted. Moreover, he refers to his rival by using his name "Mr. Harper" and the pronoun "you" to make it more personal. By using such strategy, Trudeau would like to tell Harper that all people are against his party and its policies to the extent that they do not trust him and his party anymore and that Canada needs new blood. 


\section{Visual Analysis}

The image denotes Trudeau connoting resistance to the old regime and determination. $\mathrm{He}$ is the only element depicted so he is the most salient element that is enhanced by focus, rich saturated colors and bright tones.

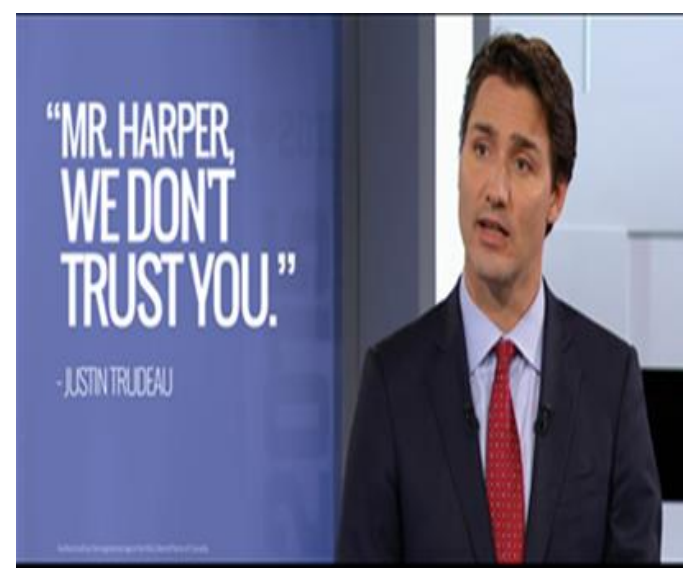

Concerning gaze, Trudeau is looking off frame which makes the image an offer one. The viewers are not invited to a relationship with Trudeau but the image maker positions them as observers to look at the image and the depicted candidate and see a determined, enthusiastic and resistant person who is unsatisfied with the Harper's policies. The offer image helps us form an opinion about the person depicted; therefore, he is depicted in this way.

Regarding pose, he is photographed standing and he is not taking up physical space. Trudeau's pose is a closed one which reflects a relative bodily control. It introduces him as a brave protector that is protecting the people by standing up against Harper and his party. We can a confident young man that is trying to persuade the viewers that he can stand up against anyone despite his young age and correct the situation spoiled by the Conservatives. As to distance, Trudeau is photographed in a close shot to let us consider the inner thoughts and feelings at an intimate level and take his stance against Harper. Such shot enables the viewers to see how Trudeau is determined to resist the corruption caused by the Harper and his party and how he defends the Canada's people and speaks on behalf of them. 
Regarding angle, the viewers and Trudeau are positioned at the same level where the image maker wants to present Trudeau as one of the viewers. Moreover, he is individualized visually through being photographed alone. Harper that is mentioned linguistically is visually excluded in order to draw the viewers' attention to Trudeau and his courage and straightforwardness.

\section{Discovering how the linguistic and visual modes work together, complement each other}

The linguistic and visual modes complement each other well. Both modes are linked through the gaze as Trudeau is looking towards his statement "Mr. Harper, we don't trust you". The image maker would like to attract the viewers' attention to the message communicated. Moreover, Trudeau is presented as one of us linguistically and visually. Linguistically, he uses the pronoun "we" to try to get closer to the voters and present himself as one of them. On the other hand, Trudeau and the viewers are positioned at the same height which means equality.

\section{Third Post}

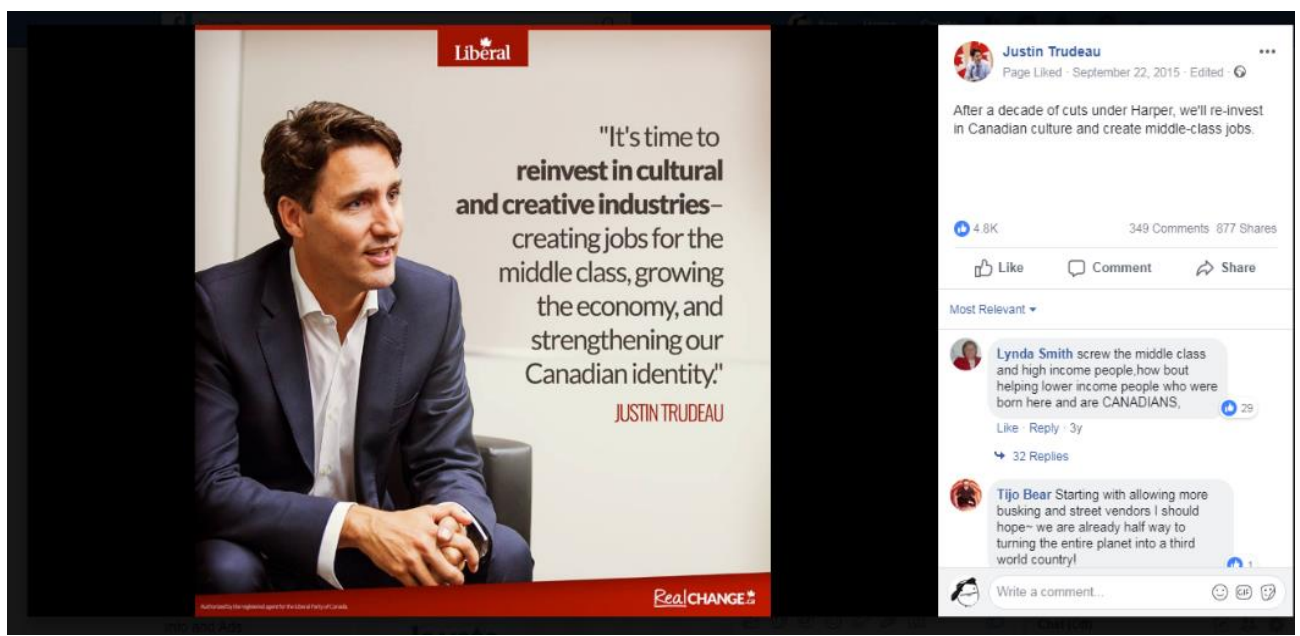

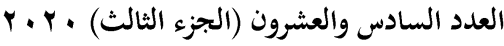

(36)

مجلة كلية التربية- جامعة عين شمس 


\section{Linguistic Analysis}

Text in the image is: "It's time to reinvest in cultural and creative industries - creating jobs for the middle class, growing the economy, and strengthening our Canadian identity."

The caption is: "After a decade of cuts under Harper, we'll re-invest in Canadian culture and create middle-class jobs"

Trudeau has a frank chat with the voters and points out his plan related to the cultural and creative industries at length so he linguistically uses processes such as "growing the economy", "creating jobs for the middle class", "re-invest in Canadian culture", "strengthening our Canadian identity" and "create middle-class jobs". Here, besides expressing his intention to reinvest in cultural and creative industries, he explains the way he will do so. Though he holds himself accountable by promising to do all these things, this states that he seeks to gain the voters' trust especially that it is his first run for the prime minister position; he would like to assure them that Canada will witness a real change if they grant him their vote. Using processes enables him to unveil the agency and time where he specifies the time "It's time to ...." and "will" and the agent "we".

"It's time to reinvest in cultural and creative industries creating jobs for the middle class, growing the economy, and strengthening our Canadian identity." presupposes that Harper neglected the cultural and creative industries and this had a negative impact on the middle and Trudeau, on his part, will try to revive such industries. This is supported by the second sentence that points out that the cuts imposed and practiced by Harper for long time hit the industries and the middle class. It is also suggested that Harper's strategy had defects where he did not observe the middle class that constitutes main part of the Canadian society or exploit such industries appropriately. While Trudeau highlights Harper's

r. r. · العدد السادس والعشرون (الجزء الثالث)

(37)

$$
\text { مجلة كلية التربية- جامعة عين شمس }
$$


mistakes and weaknesses, he unveils an effective plan that will deal with such mistakes and weaknesses.

In the conceptual metaphor in "growing economy", "reinvest in cultural and creative industries" and "re-invest in Canadian culture", "economy", "cultural and creative industries", "Canadian culture" (target domain) can be conceptualized in terms of a "child" (source domain). The attributes related to the child are transferred into the target domain. Trudeau will deal with "economy", "cultural and creative industries" and "Canadian culture" as a child that he will raise and take care of it until it becomes strong and be capable of depending on itself.

\section{Visual Analysis}

Trudeau's image connotes elegance, ambition, and new era. Trudeau's clothes present a formal look although there is no a tie. We see a candidate with a youthful look and such look reflects a confident, determined and relaxed person. The image maker wants to shed the light on Trudeau without showing any other distractions in the image. Thus, he is the largest and most salient element and such salience is supported by rich saturated colors, bright tones.

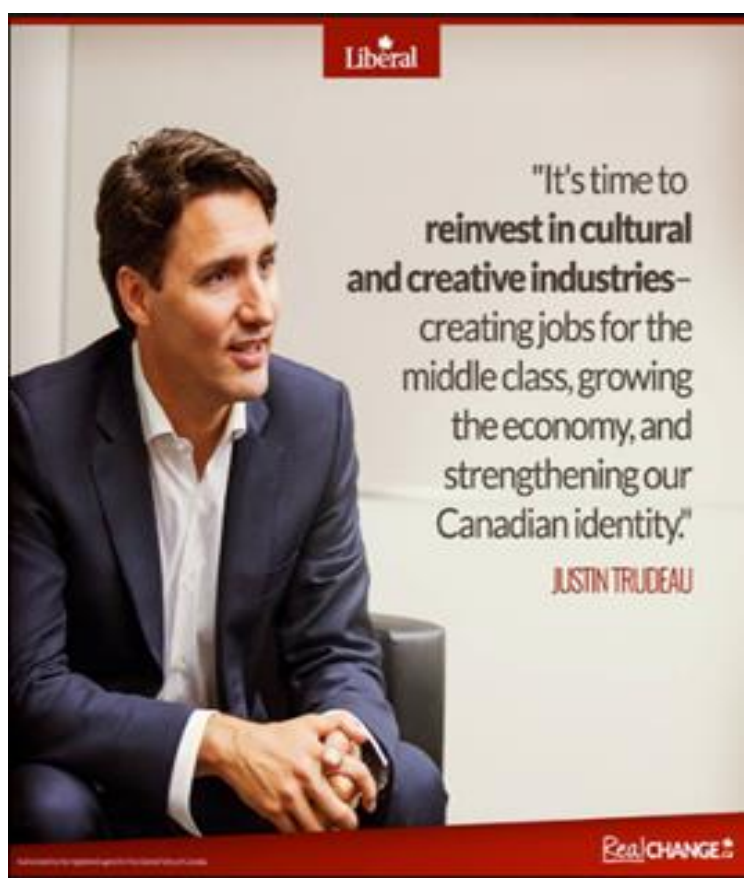

Realonuce:

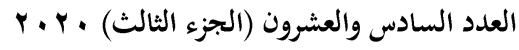

(38)

مجلة كلية التربية- جامعة عين شمس 


\section{Aya Mohamed Khaled Mohamed}

The image is an offer one as Trudeau is looking off frame. No response is asked from the viewers' part where they are just observers that are required to observe what is going on and assess the candidate's personality. Trudeau is looking at the statement "It' $s$ time to reinvest in cultural and creative industries - creating jobs for the middle class, growing the economy, and strengthening our Canadian identity." and this draws the viewers' attention to the statement that presents the corrective plan related to the cultural and creative plans and that points out that Trudeau will give such matter special attention. In addition, we can see a contemplative smile that shows that he is dealing with the serious issues wisely dispute his young age.

Trudeau's posture reflects stillness where he sits looking confident and relaxed. He is sitting on a chair and leaning forward with interlocked fingers and this makes him take a physical space. $\mathrm{Bu}$ such posture, Trudeau desires to present a person who is willing to listen to the other views and discuss them explicitly. Regarding distance, he is depicted in a medium shot to help the viewers assess him. He is presented as an active, young man who is exerting efforts to spread his views and agenda.

As to the angle, the angle is eye-leveled and this reflects that Trudeau is humble and down-to-earth. Trudeau is visually individualized. On the other hand, Harper is presented linguistically but he is excluded visually. This states that the imager maker desires to pay the viewers' attention to Trudeau only to get him the necessary support. 


\section{Discovering how the linguistic and visual modes work together, complement each other}

The analysis shows that there is coordination between both modes. First, there is a link through the gaze where Trudeau looks at the statement and such link points out that show that the issue referred to in the statement serves as one of his priorities and occupies a large part of his attention and that he is willing to carry out a dramatic change in such important field through providing the middle class with more jobs, developing the economy, and enhancing the Canadian identity. Second, in the linguistic mode, Trudeau employs the personal pronoun "we" to get closer to the voters and to involve them in implementing his plans. On the other hand, the viewers and Trudeau are visually positioned at the same length and this shows intimacy.

\section{Fourth Post}

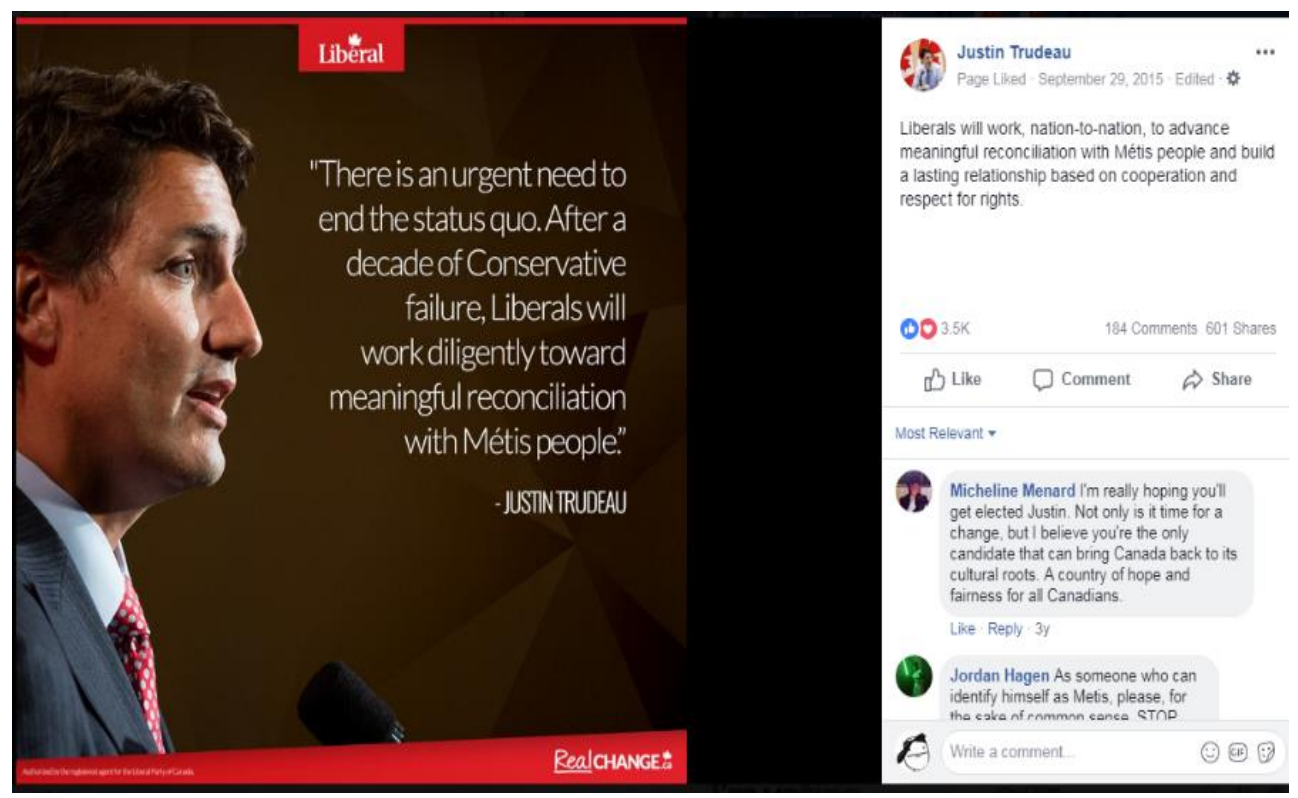

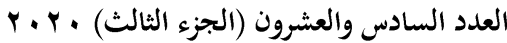

(40)

مجلة كلية التربية- جامعة عين شمس 


\section{Linguistic Analysis}

Text in the image is: "There is an urgent need to end the status quo. After a decade of Conservatives failure, Liberals will work diligently toward meaningful reconciliation with Metis people."

The caption is: "Liberals will work, nation-to -nation, to advance meaningful reconciliation with Metis people and build a lasting relationship based on cooperation and respect for rights."

Trudeau uses nominalizations to describe the position and status of Metis people in Canada instead of using processes. First, it points out that "the status quo" that resulted from the "Conservatives failure" shall be ceased, then states that his party will try to achieve "meaningful reconciliation" and "a lasting relationship based on cooperation and respect for rights." with Metis people. Nominalizations help Trudeau present succinct information without details and give the Canadians hope because such nouns connote peace, equity and bright future. Moreover, he presents the term "nation-to -nation" as a stable entity and this helps such term to become a common usage.

It is presupposed in "There is an urgent need to end the status quo" that the status of the Metis people under Harper's rule is unacceptable and that they have a lot of social and economic problems and suffer from the regime's negligence. Trudeau tries to assert that their existence is going to be acknowledged and that they will participate effectively in the Canadian community. Moreover, "Metis people" presupposes that Canada includes different groups and sects and that some of them face problems and injustice under Harper's rule.

Concerning abstraction, in the sentence "build a lasting relationship based on cooperation and respect for rights.", the relationship (target domain) can be conceptualized in terms of a 
building (source domain). The attributes related to the building are transferred into the relationship, such as durability and strength.

The social actors are represented in "Liberals", "Conservatives", and "Metis people". The social actors "Liberals" and "Conservatives" are collectivized to point out that success and failure relies on the polices adopted by the parties and Trudeau asserts that he is going to cooperate and work collectively with his party for fulfilling the public interest. "Metis people" are represented as a generic type and this points out that Canada includes groups and sects and some of them are not treated fairly under Harper's rule.

\section{Visual Analysis}

The image $\begin{array}{r}\text { displays } \\ \text { connoting }\end{array}$
Trudeau determination, courage and readiness for any confrontation. Trudeau is the only depicted element and such depiction grants him salience. The image maker uses focus and rich saturated colors techniques to show the details and expressions of Trudeau's face. We can see a candidate who criticizes his rival's policies openly.

We have an offer image where the viewers are just invited to observe the image without establishing a personal relationship with Trudeau. He is

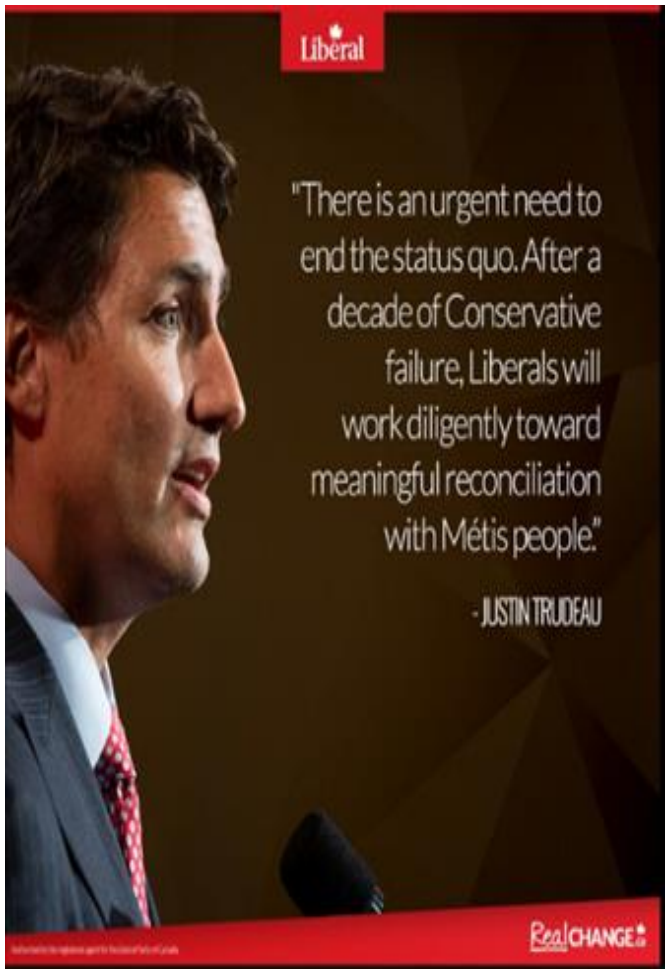

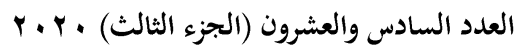

(42)

مجلة كلية التربية- جامعة عين شمس 


\section{Aya Mohamed Khaled Mohamed}

looking at the statement "There is an urgent need to end the status quo. After a decade of Conservatives failure, Liberals will work diligently toward meaningful reconciliation with Metis people." to draw the viewers' attention to the Conservatives' failures that divide Canada's people.

The image maker focuses on Trudeau's facial expressions and gaze; therefore, his posture is not obvious. Regarding distance, Trudeau is depicted in a close shot to enable viewers to assess the inner state and feelings of Trudeau. He looks determined to carry out effective changes that will lead to fulfill peace and reunite all Canada's sects.

The image maker would like to make the viewers observe the candidate and get involved with him so it depicts him through a side-on view. In addition, he is visually individualized and presented alone though there are other actors that are linguistically mentioned such as the Conservatives and Metis people. The image maker presents an image that depicts only Trudeau to reflect that he is the only solution available to solve the Metis people problems that caused by Harper.

\section{Discovering how the linguistic and visual modes work together, complement each other}

Both modes managed to complement each other through different techniques. First, the gaze links them where Trudeau's direct look at the statement points out that he seeks to achieve meaningful reconciliation with Metis people and establish a lasting relationship through cooperation and respect for rights. However, the researcher sees that there should have been a visual depiction of the Metis people for supporting such issue more. 


\subsection{Mass Appeal Images First Post}
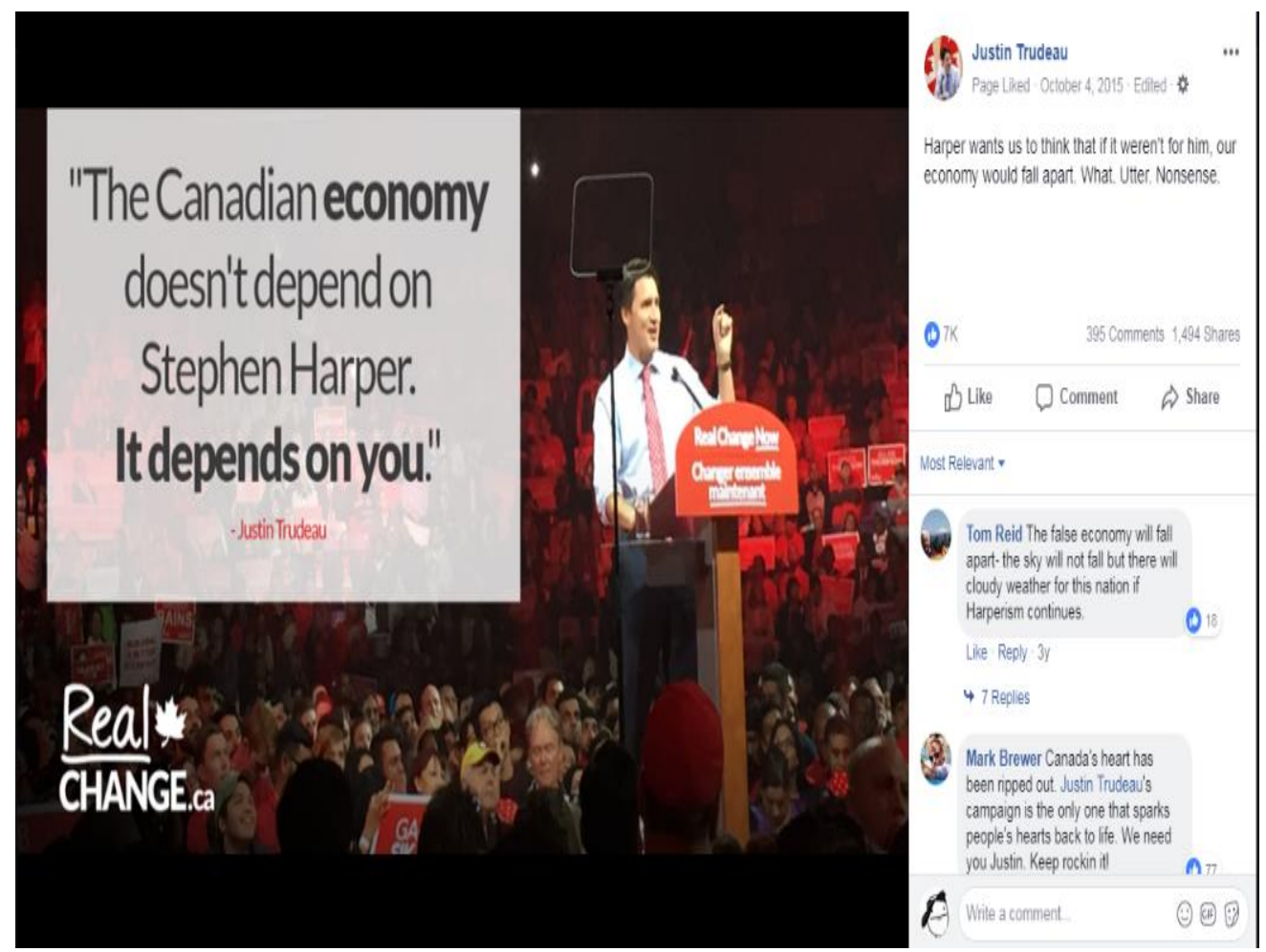

\section{Linguistic Analysis}

Text in the image: "The Canadian economy doesn't depend on Stephen Harper. It depends on you."

The caption is: "Harper wants us to think that if it weren't for him, our economy would fall apart: What. Utter. Nonsense."

The above-mentioned statements presuppose that the economy reform does not depend on one person and such reform and improvement needs the cooperation of all Canadians. It is also presupposed that there is a fearmongering on the part of Stephen Harper where he tries to mislead the Canadians into thinking that the economy's protection and stability will not be achieved without 


\section{Aya Mohamed Khaled Mohamed}

the re-election of him. Harper tries to convince the voters that he is the most appropriate candidate that can protect the economy owing to its long experience. Here the nominalization "Canadian economy" allows the use of word "Canadian" that shows that the economy requires the efforts of all Canadians and that its destiny does not rely on only one person.

Trudeau resorts to use abstractions instead of concrete details to simplify his messages and persuade the voters of them. First, personification is used to present "economy" as a person that needs care and protection. Second, the economy (target domain) is conceptualized in terms of a destroyed building (source domain) as in "our economy would fall apart" where the attributes related to the destroyed building are transferred into the economy. Trudeau would like to show that Harper is exaggerating and is trying to gain support through striking fear into them.

We can see that Trudeau is trying to get closer to the voters through using some techniques. First, he did not use the sophisticated words that the politicians usually use, and resorts to employ informal, everyday words such as "What. Utter. Nonsense.". It looks like he is having a friendly chat with his supporters. He desires to shorten the gap between him and the voters especially the young ones. In addition, he uses the pronoun "You" to establish a relationship with the voters. Through using "you", we feel that he is talking with his friends; he is trying to convince them that the economy does not depend on Harper and that they are able to deal with and overcome the economic problems. Trudeau wants to state that the economy shall not fall apart by the absence of one person and that its protection is achieved through the Canadians' effective. He also would like to make the voters feel that he is one of them through using "our economy". Trudeau uses "Stephen Harper" and "Harper" to refer to the Conservative party's candidate. It sounds more personal; Trudeau wants to point out that the economy shall not be affected by Harper's lose or win.

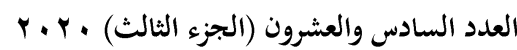

مجلة كلية التربية- جامعة عين شمس 


\section{Visual Analysis \\ The image is a mass appeal one depicting Trudeau, a microphone stand in front of him, a big number of supporters around him and the Liberals' slogan "Real change" that is put at the bottom on the left connoting big support and mutual trust. Trudeau is the most salient element in the image as he is depicted larger than the other elements and this means that he is the most important element.} Through such depiction,

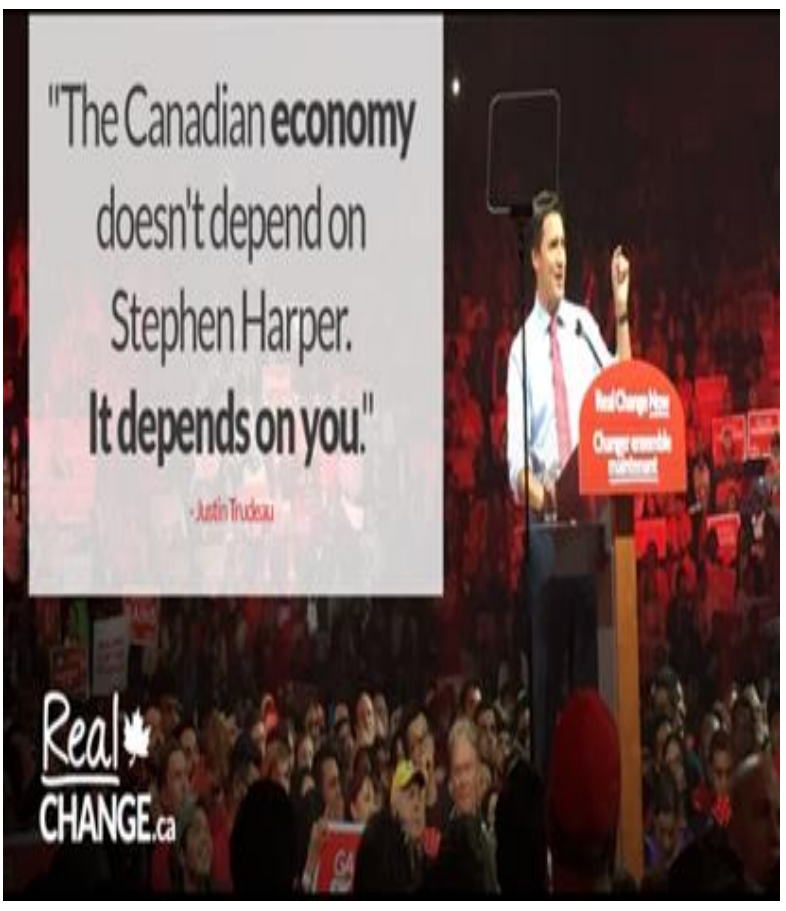
the image maker wants us to think of him as the most appropriate candidate who can be responsible for this nation. In addition, such depiction is enhanced by foregrounding Trudeau and putting him at a higher level than the supporters. On the other hand, a large number of the supporters are depicted in the background. This makes the viewers perceive him as a leader who can lead all of these people and protect Canada despite his young age.

As to the gaze, the viewers are offered an offer image as Trudeau looks off frame. This means that the viewers are just observers and nothing is required from them. The gaze is accompanied by some factors such as the smile and the finger that points to the supporters. Such smile enables him to get closer to the voters and gain their support easily. The finger pointing at the supporters reflects encouragement where he wants to tell the 
supporters that they can protect the economy themselves without depending on only one person.

Regarding posture, he is photographed standing, taking up a space and performing to the viewer through pointing at the supporters. In addition, the pose reflects an enthusiastic person that raises his friends' moral and tells them that he believes in their abilities. It also suggests openness and intimacy. He is depicted in a long shot and here the viewers are invited to be familiar with his point of view and assess his clothe and posture.

Concerning distance, the viewers confront Trudeau, but he looks slightly to the side. Such depiction suggests equality and involvement. There are generic depictions where supporters of all ages and genders are depicted and this shows that Trudeau succeeded in gaining the support of all people.

\section{Discovering how the linguistic and visual modes work together, complement each other}

There is a good coordination between the linguistic and visual modes. First, the voters are addressed through both modes. In the linguistic mode, Trudeau uses the pronoun "you" to address them and in the visual mode, he points at them using his finger. Second, he uses linguistic and visual techniques to get closer to the voters and this is carried out through the informal words like "What Utter Sense", his smile and pose and the pointing finger. $\mathrm{He}$ is presented as a friend that advices his friends and encourages them to depend on themselves. 
A Multimodal Critical Discourse Analysis of the Canadian Federal Election Candidate Justin Trudeau's Facebook Page

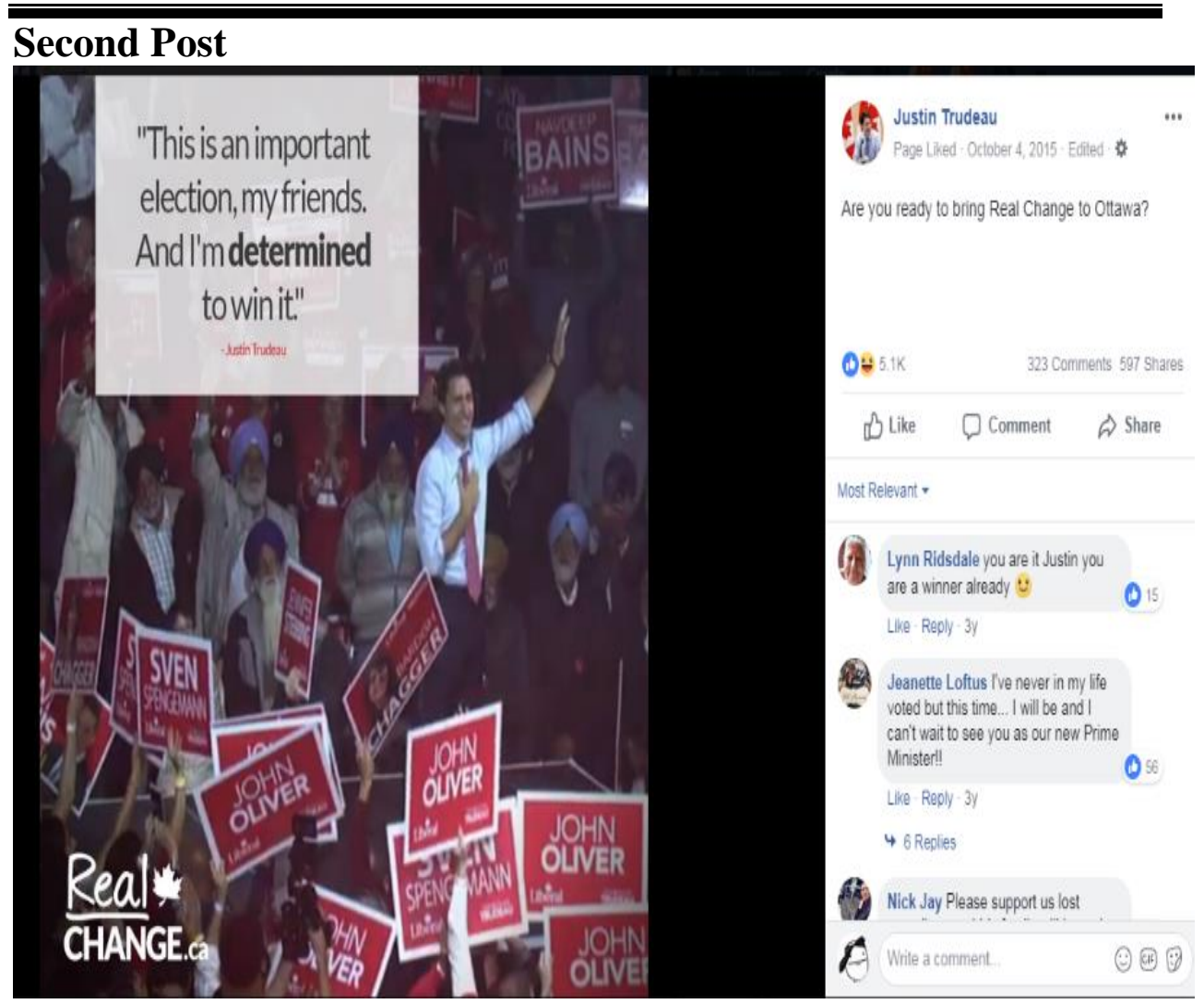

\section{Linguistic Analysis}

Text in the image: "This is an important election, my friends. And I'm determined to win it."

The caption is: "Are you ready to bring Real Change to Ottawa?"

Both statements contain nouns "an important election" and "Real Change". The use of the nouns "election" and "change" allow the use of the adjectives "important" and "real". Here, the details, agents, processes and affected people are concealed when the nouns are used. However, they enable Trudeau to communicate concise and encouraging messages without stating micro-details and to persuade the voters without revealing his ideologies overtly. "This is an important election" presupposes that such election is plays an important role in Canada's history and that the Canadians' 


\section{Aya Mohamed Khaled Mohamed}

participation and engagement will make difference. In addition, "Real Change" presupposes that Canada faces a lot of problems under Harper's leadership and the situation requires real change.

In "Are you ready to bring Real Change to Ottawa?", there is a conceptual metaphor where "Real Change" is conceptualized in terms of a "present" that Ottawa's people will give to its city. Trudeau desires to tell the Canadians that the best thing they can present to their country is casting their ballot in favour of him and his party.

Through the social actors "I", "my friends", and "you" used in this post, we can see an approachable character that seeks to shorten the distance with the voters and establish a friendship with them. Trudeau's character does not reflect the usual stereotype related to politicians; we can see a young, friendly, enthusiastic and humble politician that seeks to present a new image of the politicians.

\section{Visual Analysis}

The

image displays Trudeau, IndoCanadians and electoral signs bearing the names and photos of the Liberal candidates connoting unity, trust, youthfulness and enthusiasm. Concerning salience, the image reflects that the image maker depicts Trudeau and the IndoCanadians in the same size; however, Trudeau is foregrounded and given

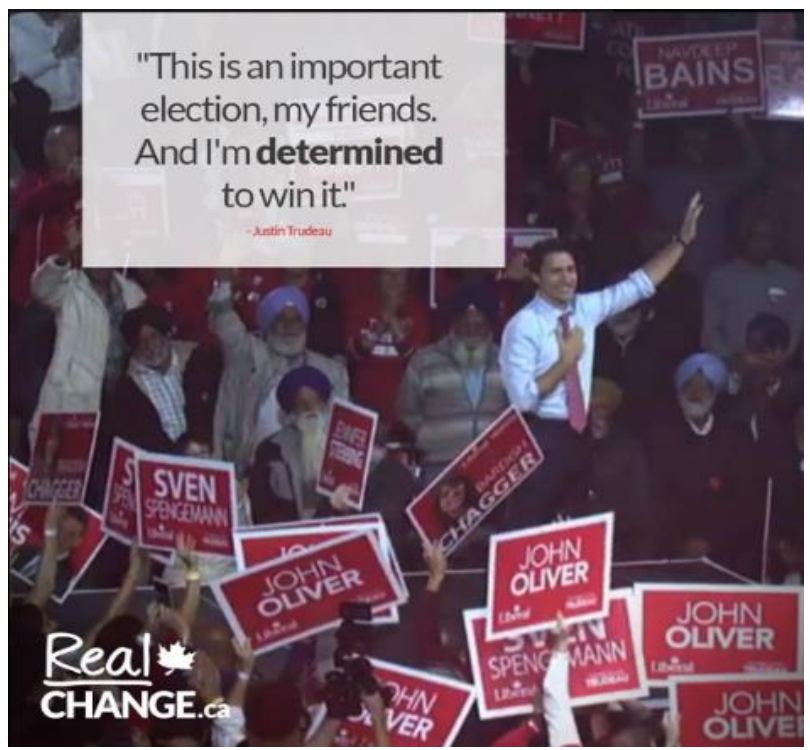
brightness. Such depiction points out that he is one of them and that he is familiar with their problems and ambitions. The electoral signs 
that display the names and photos of the Liberal candidates show that Trudeau managed to revive the Liberal Party's popularity again especially in Ottawa.

The image is characterized by a long shot and looking off frame. The viewers' role is just watching and assessing what is going on in the image. The image present Trudeau as a young man that succeeds in gaining the support of an ethnic minority through suggesting solutions to its problems and magnifying the importance of their participation in the community. Concerning his posture, he is standing and taking up space with his raising hand. He looks confident and relaxed. The gaze and pose present Trudeau as a down-to-earth and friendly person who tries to deal equally with all sects constituting Canada. His hands, the one that is on his chest and the other that greets the people, reflect that he appreciates the people depicted and such behavior makes those people feel that they are acknowledged.

The frontal angle enables the viewers to get involved with Trudeau. The image maker would like to get Trudeau the support of the people depicted and those who are watching him. There are specific depictions represented in the Indo-Canadians that are depicted in the background. Such depiction points out that the Liberal Party believes in inclusiveness and multiculturalism.

\section{Discovering how the linguistic and visual modes work together, complement each other}

The word "my friends" and his visual depiction, represented in his pose and sharing the same size with the supporters, present Trudeau as an approachable, down-to-earth politician. Moreover, in the text in the image, Trudeau states that he is determined to win the election and we can see this this visually where his posture reflects a confident and relaxed person. The Indo-Canadians in the image are not mentioned linguistically; however, Trudeau calls them "friends" and this has a bigger effect. 


\section{Aya Mohamed Khaled Mohamed}

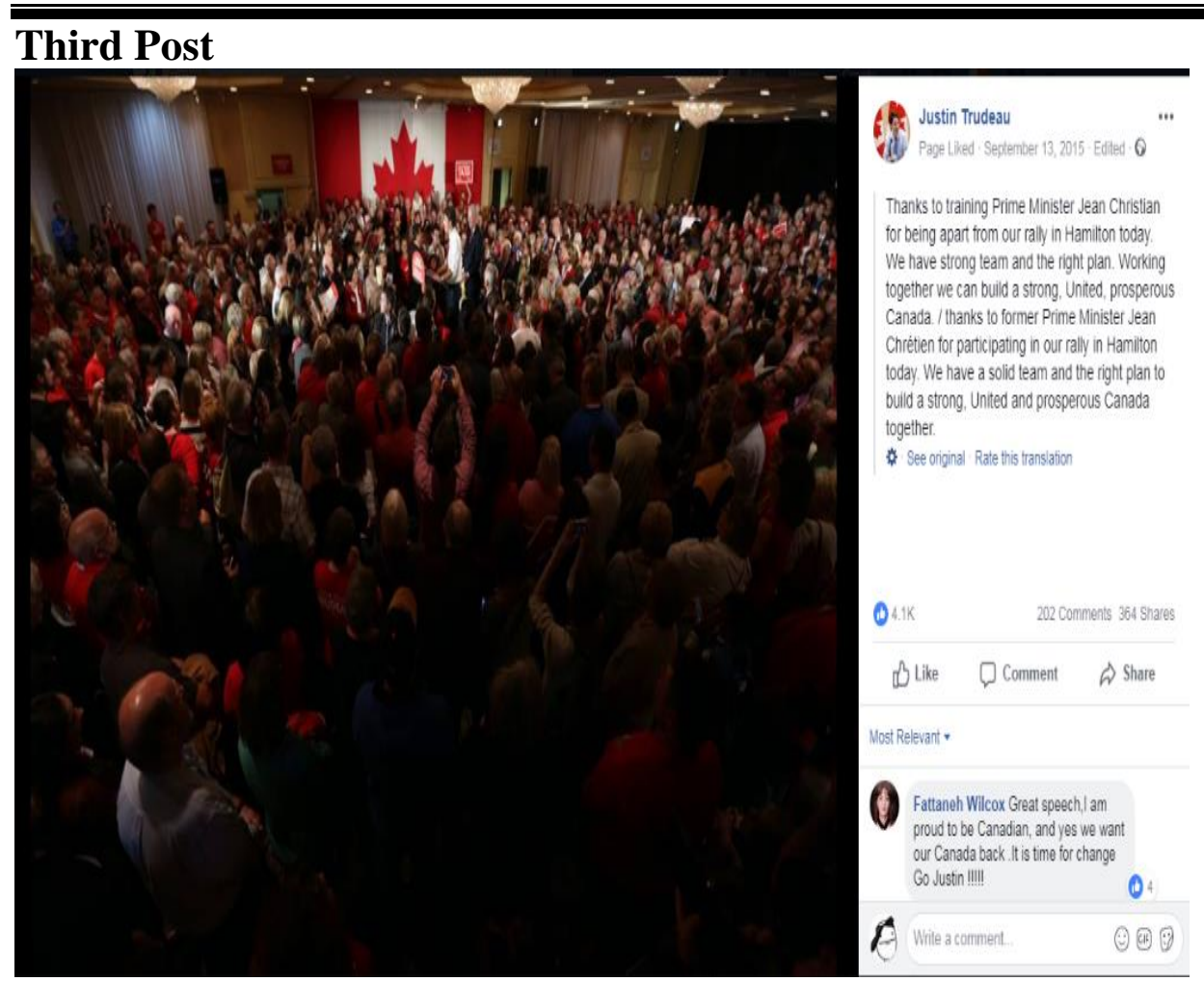

\section{Linguistic Analysis}

"Thanks to former Prime Minister Jean Christian for participating in our rally in Hamilton today. We have a solid team and the right plan to build a strong, united and prosperous Canada together."

Trudeau refers to the team and the plan as nouns. Nominalizations let him deal with the plan and the team as things and background the relevant details. Here "We have a solid team and the right plan to build a strong, united and prosperous Canada together." presupposes that Canada suffers from lacking unity, prosperity and power and needs a comprehensive plan and qualified participants to get back all of this and that the Canada's development depends on cooperation and participation of all Canadians.

Canada (target domain) is described in terms of a building (source domain) that needs efforts, time, determination and loyal 
members to be rebuilt. Metaphors enable the user to conceal some aspects. To illustrate this, the steps necessary for building the country are backgrounded by using the building metaphor; Trudeau speaks generally to not be held accountable.

The social actors used represent in "former Prime Minister Jean Christian" and "we". Trudeau uses the functional honorific "former Prime Minister" to give importance and to the participant mentioned. He makes advantage of the long history of Jean Christian to get the necessary support. The pronoun "we" suggests involvement.

\section{Visual Analysis}

The image denotes Trudeau, the former Prime Minister Jean Christian, a huge number of supporters and Canada's flag. Trudeau and Christian are standing in the middle and the supporters surround them while Canada's flag is depicted in the background. The image depicts two generations; old generation and a young one, and it is shown that the old generation supports the existence of the young

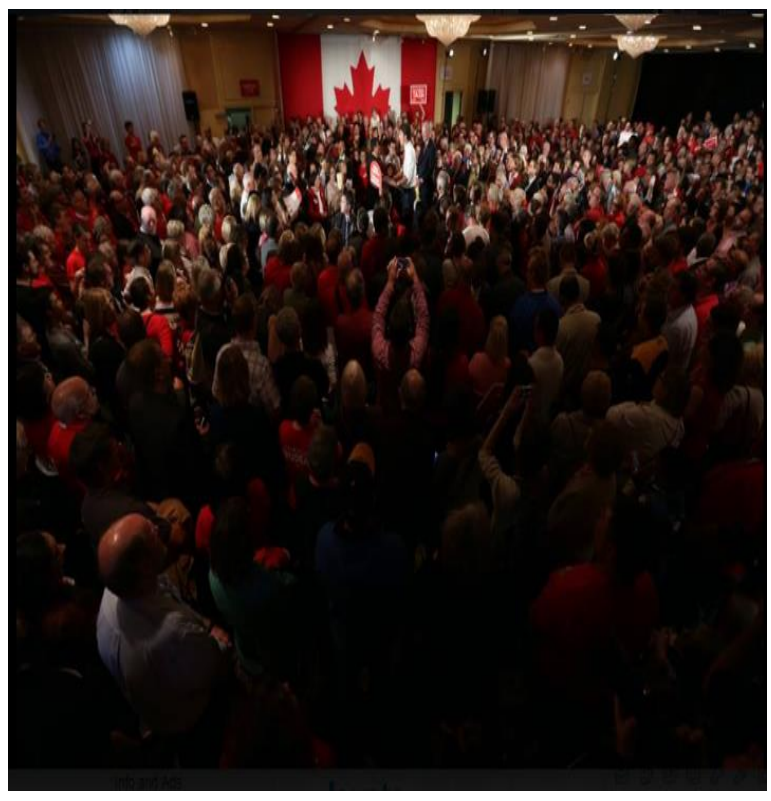
and enthusiastic one. This is also reflected by the positions of both men where Christians is standing behind Trudeau and Trudeau is talking to the voters. Positioning both of them like this means that the experienced politician Christian supports the ideas and strategies adopted by Trudeau and his party. The presence of Christian helps Trudeau obtain the old people's support. 
The largest and brightest element in the image is Canada's flag. This reflects that Canada's interest shall be prioritized and all plans and teams shall be used for developing Canada. Placing the flag in the background makes the viewers feel that Canada embraces all people and sects regardless of their differences.

In addition, Trudeau's position is higher than the supporters' and such depiction grants him authority and power and points out that he is able to be the successor of the previous experienced generations such as his father, Pierre Trudeau, and Jean Christians and that he can lead this nation successfully. A large number of people of all ages and sects support him and this reflects that he manages to persuade the people of all ages.

Trudeau is depicted in a long shot looking away and the viewers engage with him and with the other participants from angle. The vertical angle enables the viewers to look down to the depicted people and assess them objectively. Regarding his posture, he is standing talking with the supporters and here we can see a candidate that is confident of his abilities.

\section{Discovering how the linguistic and visual modes work together, complement each other}

First, the former Prime Minister, Jean Christian, is presented in both modes; however, his visual representation is more effective as it displays his support to Trudeau. Second, the image reflects a big number of supporters and they are linguistically referred to through the following "We", "United" and "together". Third, linguistically, Trudeau uses the building metaphor to state that he will build a strong and united Canada and this is visually reflected where Canada's flag is depicted larger and brighter than the other elements in the image. 


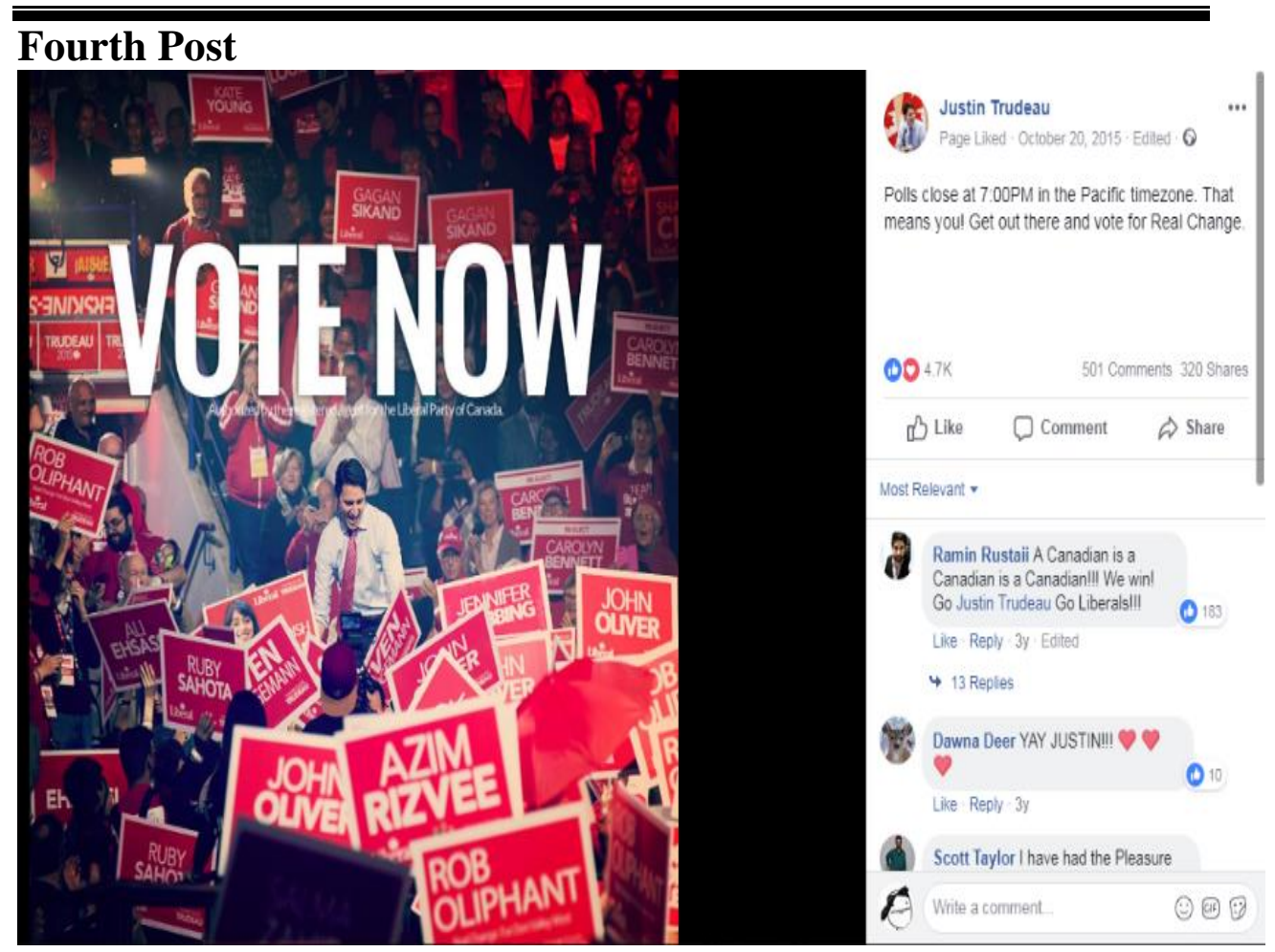

\section{Linguistic Analysis}

"Vote Now"

"Polls close at 7:00 PM in the pacific timezone. That means you! Get out there and vote for Real Change."

Trudeau uses imperatives "Vote" and "Get" to empower the voters, urge them to take an action and take part in this important election that will determine Canada's future. Moreover, he uses the pronoun "You" to get closer to the voters and make everyone feel that Trudeau is talking to him as a friend. He also uses the nominalization "Real Change" without stating any details where he would like to present a concise message to encourage the voters to cast their votes. 


\section{Aya Mohamed Khaled Mohamed}

\section{Visual Analysis}

The image depicts Justin Trudeau and a number of supporters that raise electoral signs bearing names and photos of the Liberals' candidates. Trudeau is given focus through directing bright light on him. The image maker desires to attract the viewers' eyes to Trudeau and his energetic character. The sentence "Vote now" is shining of the image and is depicted in a large size above Trudeau. Therefore, the viewers can link between the sentence "Vote now" and Trudeau and conclude that Trudeau is the best choice to their country. The signs that bear names of the Liberals' candidates are

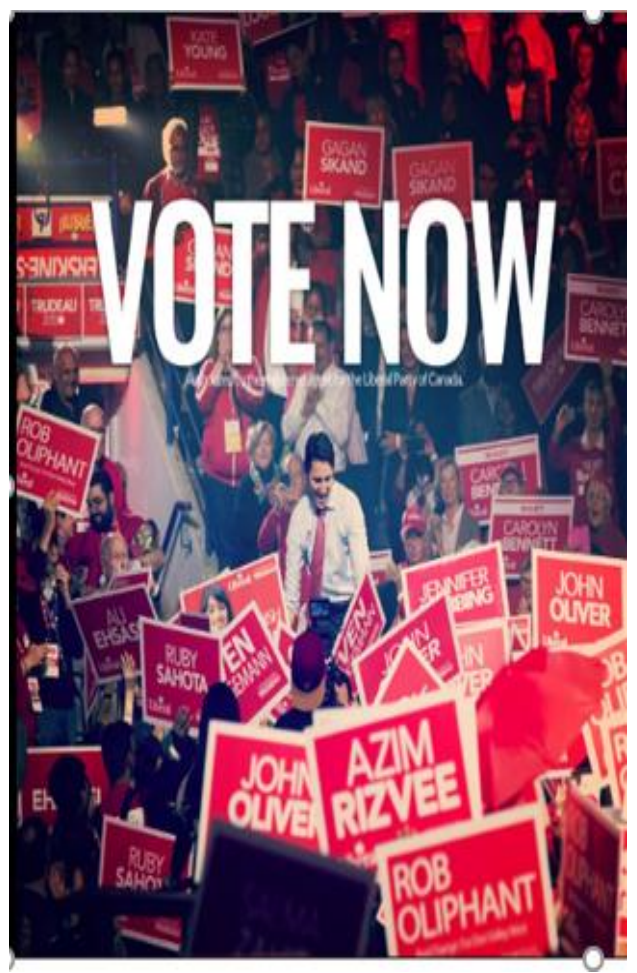
photographed in the front and Trudeau is depicted in the back. Such depiction presents Trudeau as a leader that provides support to his party's candidates in their electoral journey.

The image maker presents an offer image which means that no action is required from the viewers. The long shot enables the viewers to see the image's details and evaluate what is going on. Such shot reflects the youthful and active pose Trudeau. In addition, the eye level angle makes the viewers feel that they are part of the people displayed in the image and that they are also addressed to participate in the election. 


\section{Discovering how the linguistic and visual modes work together, complement each other}

Trudeau works on encouraging the voters to cast their votes and he carries out this linguistically and visually. Linguistically, he employs imperatives "Vote" and "Get" to do so. Visually, his active pose and dig smile encourages the voters to cast their ballot.

\section{Findings}

In the first theme, the analysis reflects that Trudeau depends on criticizing the other candidate shedding the light on his weaknesses and failures to get the voters" support. Many of Trudeau's statements presuppose that the policies of the old regime were not effective and that Canada needs a new rule and immediate changes. In addition, some of them suggest that the Canadians suffered during Harper's rule term and that many negative strategies made the Canadians lose trust in the Conservative Party.

Trudeau presents succinct information without details to give messages filled with hope and ambition through using nominalizations such as "real change". Despite the concealment of details and the parties involved through using nouns, such technique helps Trudeau get the voters' attention and support as nouns encapsulate hope and ambition.

However, in some posts, Trudeau holds himself accountable through presenting his plans at length where he uses processes such as "creating jobs for the middle class", "growing the economy", "strengthening our Canadian identity", "re-invest in Canadian culture" and "create middle-class jobs". This points out that he desires to gain the voters' trust especially that it is his first run for the prime minister position.

Moreover, Trudeau adopts a friendly conduct where he tries to get closer to the voters and to show a sense of collectivity and

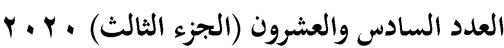

مجلة كلية التربية- جامعة عين شمس 


\section{Aya Mohamed Khaled Mohamed}

sharing responsibility. He fulfills this through employing pronouns such as "We" and "You" along with presuppositions as in "We're counting on you to be part of the change. Share this to show your support.", where this sentence suggests that the voters shall join the government for fulfilling change. Trudeau adopts the idea of inclusiveness and this is obvious in the use of the generalization "Canadians" where he is addressing all Canadians regardless of their ethnicity, religion and gender.

All images connote ambition, elegance, challenge, and determination. There is only one demand image in which Trudeau acknowledges the viewers' presence. He demands the viewers to take an action and be part of the change process. The other images are offer ones where Trudeau does not ask the viewers to make any response. The viewers are just observers and the images are offered to them as information for evaluating Trudeau's personality. The gaze in some posts is accompanied with a contemplative smile and this shows that he is wise in handling the serious issues dispute his young age.

Regarding posture, Trudeau is depicted as a relaxed, confident and determined person. In the first, second and fourth posts, Trudeau is photographed in a close shot to make the viewers get closer into his inner thoughts and adopt his view. In the third one, he is photographed in a medium shot to make the viewers assess his character.

Moreover, in the first, second and third posts, Trudeau and the viewers are positioned at the same height and this reflects that Trudeau is humble. In the fourth post, the viewers are allowed to share Trudeau's position through a side-on view.

Having analyzed the mass appeal theme, the researcher found that Trudeau continues criticizing Harper and his strategy in the election. He criticizes Harper's strategy that depends on fearmongering. Such criticism is embodied in the linguistic

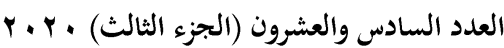

مجلة كلية التربية- جامعة عين شمس 
technique presupposition. To illustrate that, "The Canadian economy doesn't depend on Stephen Harper." and "Harper wants us to think that if it weren't for him, our economy would fall apart: What. Utter. Nonsense.". He also tries to implant trust in the Canadians, persuade them that they can overcome the economic issues without depending on Harper and this is embodied in the following "The Canadian economy doesn't depend on Stephen Harper. It depends on you.". In addition, instead of using concrete details, Trudeau employs abstractions to simplify his message and persuade the voters of such message. He uses personification and conceptual metaphors to do so. For example, "“We have a solid team and the right plan to build a strong, united and prosperous Canada together.". Here he describes Canada as a building that requires efforts, loyal members and determination to be built.

Trudeau uses slang language such as "What. Utter. Nonsense" and social actors such as "you" and "friends" to present himself as a youthful, friendly character. In addition, Trudeau tries to urge the Canadians to vote in favor of his party through imperatives "Vote" and "Get" that capsulate encouragement and incentive to address the constituents.

Visually, the images denote people of different ages, ethnicity and genders and connote huge support, unity and mutual trust. Concerning gaze, all images are offer ones which enable us to assess the images profoundly. Trudeau's postures in this theme are important. He, in the first, second and fourth images, takes performs to the viewers by pointing his finger at them and raising his hand and such poses shows him as active, enthusiastic person.

Regarding distance, Trudeau is photographed in long shots in all. Such depiction let the viewers assess Trudeau's poses and clothe. Concerning angle, the viewers confront Trudeau in the first, second and fourth images and they are allowed to get involved with him while in the third image, there is a vertical angle in which the viewers are looking down to the depicted participants and such angle lets us assess what is going on more objectively.

r. r. العدد السادس والعشرون (الجزء الثالث)

(58)
مجلة كلية التربية- جامعة عين شمس 


\section{Conclusion}

To sum up, the researcher applies Multimodal Critical Discourse Analysis to shed the light on the techniques used the techniques used by Trudeau to persuade the voters to cast their ballot for him, to detect his ideology and to show how the linguistic and visual modes work together, complement each other in communicating information on the Trudeau's identity and agenda. It is found that Trudeau uses very effective techniques such as nominalization, abstractions, posture, gaze and distance to get closer to the voters and convey his electoral agenda. Such techniques show that he adopted inclusiveness and multiculturalism as his ideologies to get the support of all Canadian regardless of their differences. It is also discovered that both linguistic and visual modes complement each other and that they are of equal importance. 


\section{References}

Evan, V. \& Green, M. (2006). Cognitive Linguistics: An Introduction. Edinburgh University Press.

Federal Election Results 2015. Justin Trudeau's Liberals to form majority government. (2015). Retrieved January 8th, 2018 from http://www.cbc.ca/news2/interactives/results-2015/

Justin Trudeau Posts are taken from https://www.facebook.com/JustinPJTrudeau/

Kress, G. and van Leeuwen, T. (1996). Reading Images: The Grammar of Visual Design. London: Routledge.

Machin, D., \& Mayer, A. (2012). How to Do Discourse Analysis: A Multimodal Introduction. Sage.

Nardelli, Alberto. (2015). Canada election 2015: a guide to the parties, polls and electoral system. Retrieved February 26th, 2018 from https://www.theguardian.com/world/2015/aug/03/canada-election-parliamentstephen-harper

O’Halloran, Kay, Bezemer, Jeff \& Jewitt, Carey. (2016). Introducing Mutlimodality. London and New York: Routledge.

OHalloran, K. L. (2011). Multimodal Discourse Analysis. In K. Hyland and B.Paltridge (Eds). Companion to Discourse. London and New York: Continuum. Tenhunen, S. \& Karvelyte, V., (2015). "The Role Played By Social Media In Political Participation And Electoral Campaigns”. Online publication by European Parliamentary Research service Blog. Available at: https://epthinktank.eu/2014/02/12/the-role-played-by-social-media-in-politicalparticipation-and-electoral-campaigns/

Tenorio, E. Hidalgo. (2011). Critical Discourse Analysis, An overview. Nordic Journal of English Studies, 10(1), pp.183-210. DOI: http://doi.org/10.35360/njes.247

van Dijk, T. A. (1998). Critical Discourse Analysis. In Tannen, Schiffrin and Hamilton (Eds.), Handbook of Discourse Analysis (352-371). Blackwell Publishers.

van Leeuwen, T., \& Jewitt, C. (2001). Handbook of visual analysis. Los Angeles: Sage.

Yglesias, Matthew. (2015). The 2015 Canadian Federal Election, explained. Retrieved February 26th, 2018 from https://www.vox.com/2015/8/6/9109669/2015-canada-federal-election 